\title{
A Study on Water Logging Problem of Rangpur City
}

\author{
Musharat Sabnam ${ }^{1}$, Muntasir Tabasum ${ }^{2}$, Faruque Abdullah ${ }^{3, *}$ \\ ${ }^{1}$ Department of Civil Engineering, Rajshahi University of Engineering \& Technology, Rajshahi, Bangladesh \\ ${ }^{2}$ Department of Geography and Environment, University of Dhaka, Dhaka, Bangladesh \\ ${ }^{3}$ Department of Building Engineering \& Construction Management, Rajshahi University of Engineering \& Technology, Rajshahi, \\ Bangladesh
}

\section{Email address:}

musharatsabnam96@gmail.com (M. Sabnam), muntasir.tabasum@gmail.com (M. Tabasum), abdullah@becm.ruet.ac.bd (F. Abdullah)

${ }^{*}$ Corresponding author

\section{To cite this article:}

Musharat Sabnam, Muntasir Tabasum, Faruque Abdullah. A Study on Water Logging Problem of Rangpur City. International Journal of Environmental Protection and Policy. Vol. 9, No. 4, 2021, pp. 77-85. doi: 10.11648/j.ijepp.20210904.12

Received: August 10, 2021; Accepted: August 19, 2021; Published: August 27, 2021

\begin{abstract}
Rangpur is one of the major metropolitan cities in the Northern part of Bangladesh. It has become a metropolitan city in 2018 with a population of almost 16000000 . Water logging is one of the major problems in the Rangpur City. In recent years most of the city has been inundated due to heavy rainfall in a short period of time during monsoon season. This year a $433 \mathrm{~mm}$ rainfall for 12 hours made the whole city water logged almost for 2 days. The major causes working behind this situation are weak and unplanned drainage system and topographical condition. Geographically the elevation of the main Rangpur City is lower compared to the surrounding areas which results in water logging. The drainage system was also unplanned and defective from the beginning of the formation of Rangpur city. Inadequate and poor drainage system, low maintenance and lack of dredging are making the condition worse. Unplanned building construction and increased population in locality has accelerated and prolonged the water inundation. Due to the up growing inhabitance, number of open lands and ponds are decreasing and moreover the poor drainage system is preventing the rainwater from draining away. The inactiveness and endangered condition of the Shama Sundori canal flowing throughout the city enhanced the acuteness of water logging. The sufferings in daily life have no bound among the residents due to water logging in the rainy season. The water bound people have no pure drinking water and food and have lost their valuable assets, furniture, houses, cattle and crops. This also causes physical damages to the roads and buildings as well as environmental damages. The study focuses on the recent scenarios of water logging and tries to find out and analyze the causes of water logging. The report also proposes a more effective solution to reduce the on growing threat of water logging problem for Rangpur city.
\end{abstract}

Keywords: Water Logging, RpCC, Drainage System, SWM, Urban Area

\section{Introduction}

Rangpur is one of the renowned cities in Bangladesh. It is the largest city in the northern part of the country. Rangpur was declared a district headquarter on 16 December 1769. It is one of the oldest municipalities, established in 1869. [1] The municipal office building was constructed in 1892 under the precedence Raja Janaki Ballav Sen. Rangpur became City Corporation on 28 June 2012 and a metropolitan city on 16 September 2018. [2] It holds an up growing number of populations of 796,556 (sesus-2017) within an area of 207 $\mathrm{km}^{2}$. The average elevation of this city is $34 \mathrm{~m}$. [3] After declared as a division in 2010 the population growth has been accelerated as well as the unplanned settlements without any proper supervision. The increased population contributes an additional number of wastes which eventually ends up in the drainage system. As a result, the city has become a victim of an adverse drainage system and improper waste management system. In some locality the settlements have been developed without having any drainage system. Though there are some drains in some areas but these are inadequate considering the up growing number of households. The existing drainage system is not well maintained. As a result, the city becomes inundated every year during the rainy season. The water logging situation has turned into a common phenomenon in recent years. In 2011, 2014, 2018 and 2020 the major part of 
the city remained water logged for several days after one- or two-day's heavy rainfall. 2020's water logging situation can be mentioned as around 50,000 residents of the city corporation were marooned as the poor drainage system was preventing the rainwater from draining away. [4] Due to unprecedented torrential rains, the canals (ShamaSundori and KD Canal) have also become choked with water hyacinth, which has contributed to waterlogging in the city. The Liberal fighter Akbar Hossain, Chairman of the Shushashoner Chapter Jonno Nagorik of Rangpur stated, accusing the city corporation of a bad drainage system behind water logging problem, saying there is no planned water drainage system presently constructed in town. [5] Beside this, the former Ward-18 councilor Ripa Akhtar criticizes the Rangpur City Corporation for the situation because of a lack of drainage. [6] This recent situation is producing pollution and environmental degradation in the city. A proper and active drainage system will come to rescue the residents of the Rangpur City from the water logging situation. Due to the unplanned urbanization this problem can be more acute in recent future. Hence sufficient research works have not been conducted regarding this concern. This study focuses on indicating the acuteness of this problem and to analyze the main causes working behind it. The study also tries to find a solution to reduce the waterlogging situation for healthy environment and sustainable urban development of the Rangpur City.

This article tries to make an inventory of the recent water logging problem of Rangpur City as well as to analyze the existing poor drainage system of the city. Beside this we tried to find out the causes and effects of the water logging problem and to suggest some recommendations to reduce the water logging problem.

\section{Literature Review}

Nureen F. Anisha and Shahadath Hossain in their research paper "A Case Study on Water Logging Problem in An Urban Area of Bangladesh and Probable Analytical Solutions", tried to describe the flooding situation of Teknaf a small urban area of the southern part of Bangladesh. Though the flood is a common phenomenon in this country during the monsoon season but the frequency and the intensity have been increased nowadays. Despite different reasons one of the main causes is the inactive and unplanned drainage system of this area. The researchers have analyzed the existing drainage pattern of this area and proposed a better and suitable drainage system to reduce the water logging problem of Teknaf. [7]

Wahedul Islam and Subaran Chandra Sarker showed the free land, open wet spaces as well as ponds are getting filled for building construction in past two decades. Open land spaces decreased at a rate of 65 hectors per year, resulting in 1220 hectors decrease within 1998-2000 and 2235 hectares decrease till 2014. Even the rate of wet lands converting to settlement by earth filling was alarming as wet land decreased by $10 \%$ from 1989 to 2014. [8]
M. Ali Ashraf and Md. Shariful Alam Chowdhury in their research titled "Drainage Planning in the Cities of Bangladesh: Case Study of Drainage and Water Logging in Chaktai Commercial area, Chittagong" studied the operative integration of a drainage network in the land use plan for the city. According to physical characteristics, topography, catchment area and the paths of existing drainage channels, the urban area has been divided into 10 drainage areas. The study illustrates the nature, intensity and the effects of the water logging problem in the daily life of Chaktai area in Chittagong. After the approval of Drainage Master Plan in 1999 the city didn't notice any effective implementations rather experiencing water logging almost every year. The paper proposed a detailed plan for drainage, sewerage, SWM renovations and construction of drains and culverts for gravity drain out. [9]

Sagor Bosunia on the study based on the report "Water Logging and Drainage System of Rangpur City Corporation" made an inventory of existing drainage system in ward no 18 and 20 . The analysis found that $69 \%$ of the study area has drain, $16 \%$ have no drain, $10 \%$ drains are in under constructions and 5\% area had the drains past of RCC. Most of them are poorly constructed, under sized and low maintained which eventually accelerating the water logging situation. [10]

LGED project proposed a long-term development plan for Rangpur City Corporation. This report aims to accomplish the physical, social, economic and environmental requirements of a fully developed city corporation. Several plans such as Administrative Reform Plan (ARP), JICA Loan Project and various subprojects like canal renovation; drains, bus terminal, public toilets and community infrastructure construction and development of waste management system have been suggested. [1]

Md. Ferdous Sarker and Md. Zakiur Rahman surveyed the present solid waste management system of Rangpur City. The waste manage network only includes 15 wards among 33 wards producing 16.46 tons per day. About 50\% city corporation area are out of SWM. They proposed a GIS data base to regulate the waste management. [11]

Khondoker G. Tawhid in his study "Causes and Effects of Water Logging in Dhaka City, Bangladesh" described the physical, social, economic impacts of water logging in Dhaka city during the monsoon periods. This regular occurrence has become a challenge for the authorities while dealing with tremendously growing population density. Different vital causes like insufficient drains, improper waste management, illegal housing and over population are considered. An implication of proper drainage plan with the assistance of governmental and nongovernmental organizations can be the solution according to the research. [12]

Rahman, M. S. Hossain, N. and et al in their study "Investigation on Causes and Effects of Waterlogging in The Southern Part of Bangladesh" analyzed the severe annual waterlogging situation during the monsoon period. The study focused to explore the key causes of waterlogging and its adverse effects on different Noakhali Pouroshavas. The 
authors suggest that mutual coordination and awareness between government-private authorities with local public are indispensable for the resolution of the problem efficiently and sustainably. [13]

\section{Methodology}

In the study a series of sequential analytical processes have been followed. For the quantitative analysis different secondary data have been collected from different sources. The secondary data analysis has assisted to identify the major causes of water logging and understand the existing drainage system of this area. A questionnaire survey has been conducted for qualitative analysis. The field survey helps to find out the problems and effects of water logging especially to the residents. These leads to develop a suitable solution to this existing water logging problem of Rangpur City.

\subsection{Selection of the Study Area and Location}

Rangpur City Corporation is located at the coordinate of $25^{\circ} 37^{\prime}$ to $25^{\circ} 54^{\prime}$ North latitude and $89^{\circ} 09^{\prime}$ to $89^{\circ} 21^{\prime}$ ' East latitude (Figure 1). It has an area of $203.63 \mathrm{sq} \mathrm{km}$ with approximately population of 7,96,556. RpCC [Rangpur City Corporation] is consist of 33 wards. [14] As one of the rapidly growing metropolitan cities Rangpur has been facing water logging problem during monsoon periods in recent years. The acuteness of this water congestion in the main city area has played the main cause to select this study area.

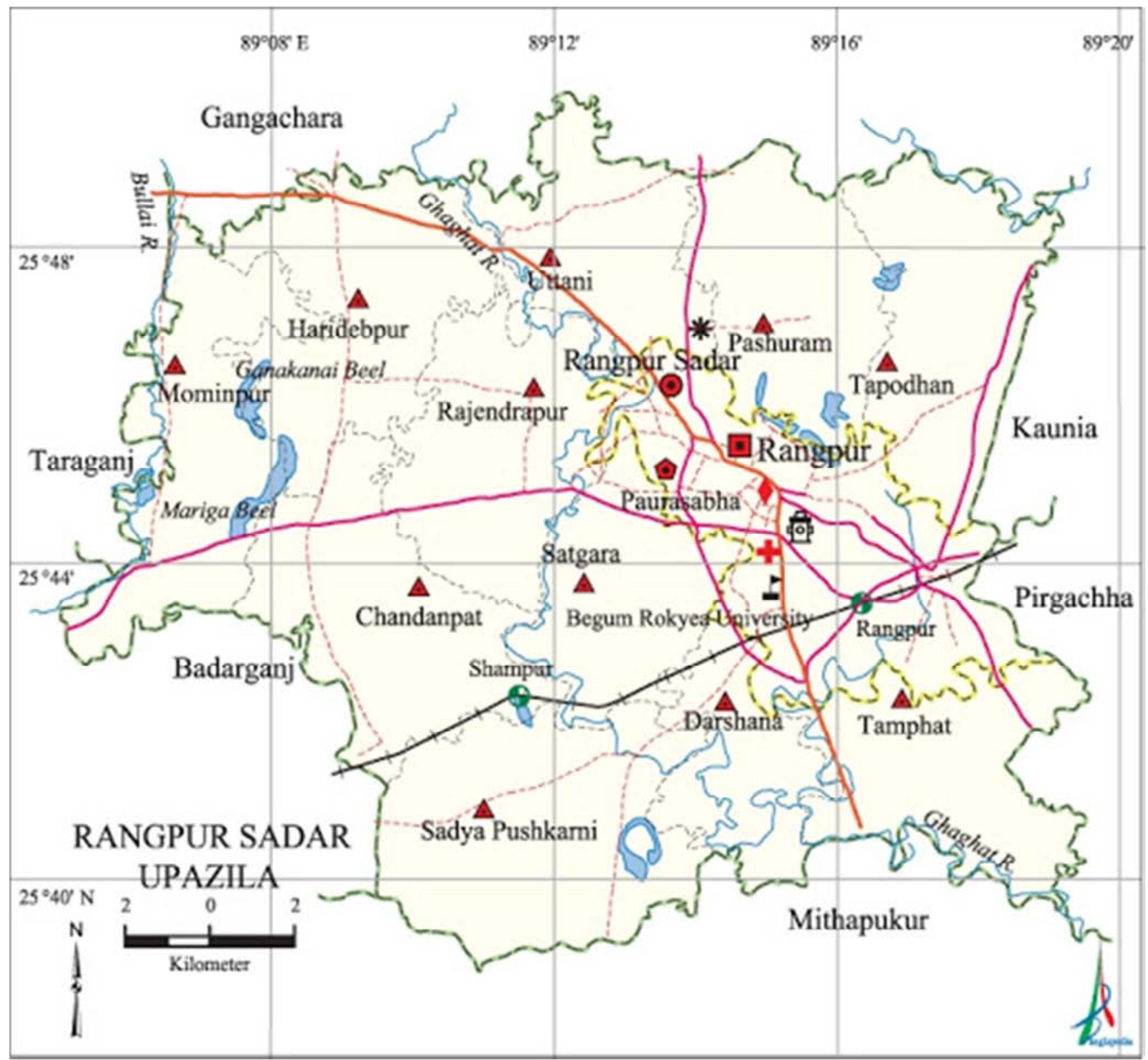

Figure 1. Study Area Map. 


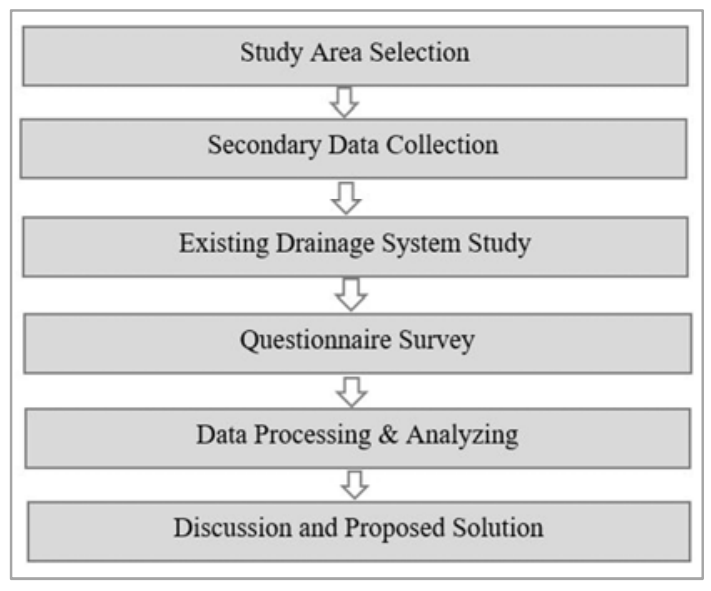

Figure 2. Study plan.

\subsection{Data Collection and Analysis Process}

The ArcGIS 3.2 software has been used for map representation. MS word and MS Excel were used for graphical presentation of data and information in general. A questionnaire survey has been prepared for field survey and the SPSS software is used to convert the qualitative data into quantitative data according to the process shown in Figure 2.

A) Secondary data collection: RpCC, LGED, BWDB, BMD, BBS

B)Primary data collection: Questionnaire Survey

\section{Discussion and Result}

The increasing number of water logging in the RpCC area is the result of different factors working simultaneously over the years. This study is focused on the present conditions of the area and tries to find out the main causes of water logging in RpCC. The sole purpose of the questionnaire survey has been to bring out the adverse effects of this situation on the local lives.

\subsection{Present Parameters}

The water logging condition of a certain area depends on several parameters. If most of the factors are present in the locality, then the inundation situation is more vulnerable. The intensity of the water logging condition relays on the occurrence, frequency and amount of these factors. The most prominent factors working behind the RpCC water logging situation are given below

\subsubsection{Existing Drainage System}

The Ghagat River situated at the Northwestern part plays an important role in the water management system of the RpCC. Other mentionable water bodies of the city are Chiklir Bill and Radhasagar Lake. But the drainage system of the city is mainly dependent on Shama Sundori Canal flowing from northwestern to the southeastern part. The canal not only serves in the drainage system but also maintains the ecological balance of the main City.
Table 1. Type of Drains in RpCC.

\begin{tabular}{ll}
\hline Drain Type & Length $(\mathbf{k m})$ \\
\hline RCC \& masonry Drain & 60 \\
Earthen Drain & 175 \\
Total & 235 \\
\hline
\end{tabular}

Source: RpCC Report, 2014

Table 2. Existing Drainage Situation of RpCC.

\begin{tabular}{ll}
\hline Name of the Component & Present Quantity (km) \\
\hline Canal/Khal/Outfall Drain & 60 \\
Primary Drain & 20 \\
Secondary Drain & 60 \\
Tertiary Drain & 90 \\
Cleaning Blockage & 175 \\
Total Drain Length & 405 \\
\hline
\end{tabular}

Source: RpCC Report, 2014

The present number of drains is inadequate according to the growing number of populations of the city. As a result, the insufficient number of drains are incapable to flash away the excess monsoon water along with the daily discharge.

\subsubsection{Rainfall}

Rainfall was not very prominent in this particular region of Bangladesh earlier rather it was known as a drought prone area. But during the monsoon periods from June to August the study area is hit by medium to heavy rainfall nowadays. An increase in the rainfall intensity has been noticed from the past few years. In September 2020 Rangpur experienced an intense torrential rainfall of $433 \mathrm{~mm}$ for only 12 hours which broke 60-year record of rainfall. [15]

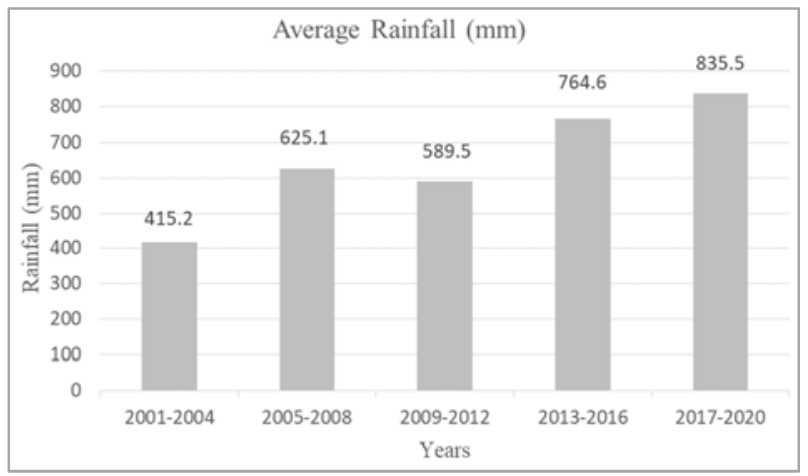

Source: BMD-2020

Figure 3. Average Rainfall (mm) (2001-2020).

As the rainfall has increased, the number of day's water logging has increased. This situation is noticed more in past few years.

Table 3. Number of day's water logging.

\begin{tabular}{lllllllllll}
\hline Days/Years & 2011 & 2012 & 2013 & 2014 & 2015 & 2016 & 2017 & 2018 & 2019 & 2020 \\
\hline$(1-3)$ & $\sqrt{ }$ & $\sqrt{ }$ & & $\sqrt{ }$ & $\sqrt{ }$ & & $\sqrt{ }$ & & & \\
$(3-5)$ & & & $\sqrt{ }$ & & & $\sqrt{ }$ & & $\sqrt{ }$ & $\sqrt{ }$ & \\
$(5-7)$ & & & & & & & & & & $\sqrt{ }$ \\
\hline
\end{tabular}

Source: BWDB, Rangpur. 


\subsubsection{Population Projection}

After the declaration in 2010 of division Rangpur is facing a tremendous migration rate. The ICGP team of RpCC has predicted that the population will cross 3.8 million within 50 years. This excess population will grab most of the open places, wetlands, ponds leaving no free spaces to drain out the surplus water during the monsoon periods in near future.

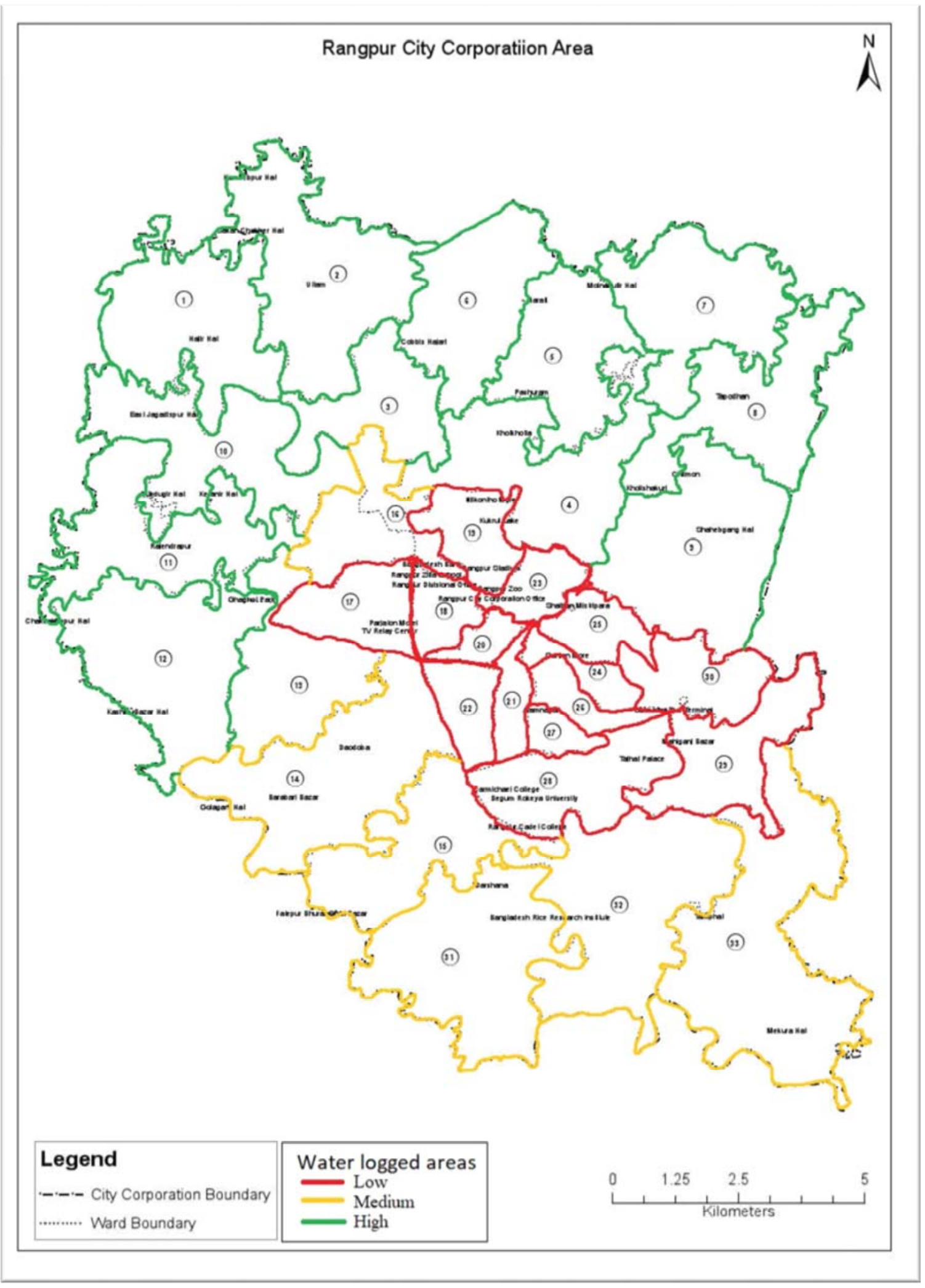

Figure 4. Most Water Logged Areas of RpCC. 
Table 4. Population Projection of RpCC

\begin{tabular}{lllll}
\hline $\begin{array}{l}\text { Present Population } \\
\text { Million }\end{array}$ & $\begin{array}{l}\text { Growth Rate (Percent per } \\
\text { year) }\end{array}$ & $\begin{array}{l}\text { Population (after 5 years) } \\
\text { million }\end{array}$ & $\begin{array}{l}\text { Population (after 25 years) } \\
\text { million }\end{array}$ & $\begin{array}{l}\text { Population (after 50 years) } \\
\text { Million }\end{array}$ \\
\hline 0.9 million & 2.97 & 1.04 & 1.87 & 3.89 \\
\hline
\end{tabular}

Source: ICGP Team, RpCC \& BBS Census-2011

\subsubsection{Most Water-Logged Areas}

Rangpur City Corporation has 33 wards. The main city consists of ward no 12 to 30 among which 16-28 wards hold majority of the population and households. Despite being the center of the city area, these wards possess an insufficient number of drains and proper waste management system. Moreover, this area is the main attraction to the migrants.

Hanuman Tola, Islambagh, New Jummapara, Munshipara, Keranipara, Robertsonganj, Kotowali Thana area, Mahiganj, Haragachh, Shalban, Ganeshpur, Kamarpara, Mulatol, Masterpara, Bonanipara and Lalbagh are the areas which face most severe situation every year during the monsoon. The drainage system of the suburban area as well as the old pourosova area has failed to meet the demand. Residents of the city suffered from at least $2 / 3$ feet water congestion after $433 \mathrm{~mm}$ of heavy rainfall for 24 hours in September 2020. Majority of the dwellers became water bounded and daily lives were at a stack.

\subsection{Causes of Water Logging in RpCC}

Rangpur city is now the victim of frequent water logging in recent years. Not only one cause is responsible but several factors are working behind it. The combined effects of these causes are contributing to the annual return of this water drowned condition in RpCC area. The most causative factors are given below

\subsubsection{Drainage System}

The drainage system of any area specially City Corporation area is focused on accumulating and washing away waste materials in a systematic way from the locality. The existing drainage system is not sufficient enough to fulfill the demand of increasing population of the RpCC area. Lack of long lasting and strategic structural implement as well as maintenance and awareness are provoking the adversity of the situation.

a) Insufficient \& Narrow Drain Size:

Most of the drains were constructed before the establishment of RpCC, when Rangpur was a municipality. The population load over the drains has increased but the sizes of the drains still remain the same. These types of narrow drains don't able to carry flood water from city area and it causes water logging mostly. Although RpCC has already taken some initiatives to develop the drainage and systems, but still not sufficient.

\section{b) Poor Construction:}

Present drains are mostly masonry constructed or earthen drain $(175 \mathrm{~km})$. Maximum are constructed a long time ago to meet the temporary need by local community without properly considering the design population or leaving any further space to extend or reconstruction. Though City Corporation has constructed some RCC drains $(60 \mathrm{~km})$, but most of them are chocked with solid waste and out of maintenance. In some places drain construction is stopped in the middle. Though unfinished drains are visible but unable to serve the purpose.

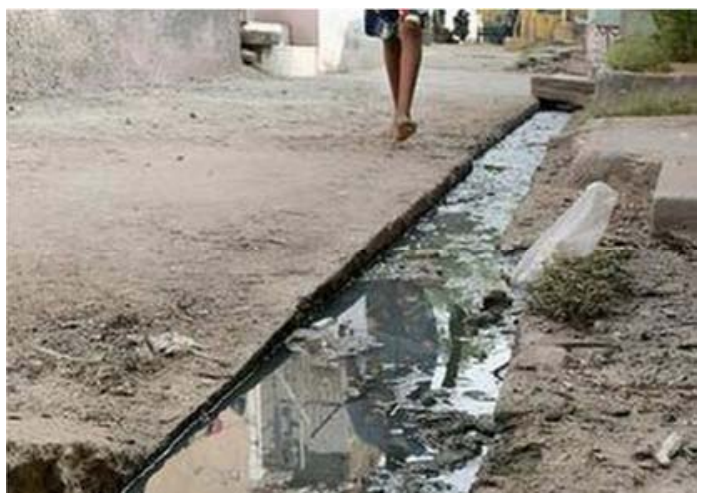

Figure 5. Narrow roadside drains in ward 21.

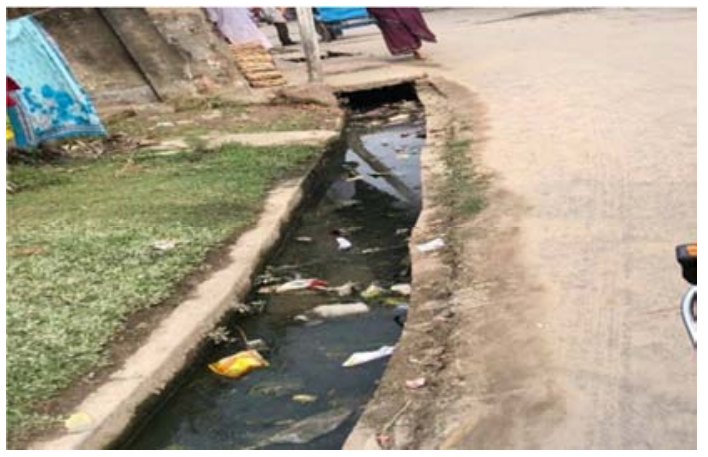

Figure 6. Poorly constructed roadside drains.

\section{c) Low Maintenance:}

Most of the existing drains of the main city area are inactive. The reasons working behind this lethargic condition are over load, unplanned construction and lack of proper maintenance. Regular cleaning, reconstruction and development of capacity can solve this long going problem. The lack of dredging, drains are becoming full with waste particles causing water logging in the ward no. 16-28 of RpCC mostly.

\subsubsection{Unplanned Building Construction}

Rangpur city is considered as the heart of northern part of Bangladesh providing necessary facilities such as university, medical colleges, nursing college, private clinics, polytechnic institute, divisional headquarters, shopping markets, show rooms, Cadet College and all type of facilities. People become more interested to buy land after the establishment of City Corporation and constructing unplanned building 
without maintaining building code and leaving no necessary space to install a proper drainage network. So, this unplanned building causes water logging badly.

\subsubsection{Incapability of ShamaSundori Canal \& Ghagot River}

The historical ShamaSundori canal was excavated to balance the ecosystem and serve drainage purpose. But this canal totally failed to accomplish its duty. This canal is a branch of Ghagot River. In past, the Ghagot water used to flow through the canal washing away its wastes. Now, canal bed is 10-15 ft higher than the Ghagot River bed and lost its natural capacity. The ShamaSundori and KD Canal have also become choked with non-decomposable plastics, poly bags, domestic and industrial wastes and water hyacinth, which has contributed to waterlogging in the city. After establishment of CC in 2010 the renovation of the canal was taken in some part such as Keramoti Mosjid area, Keranipara and Shapla Chottor area of the city. Due to low maintenance of RpCC and lack of awareness of the inhabitants the condition remains the same.
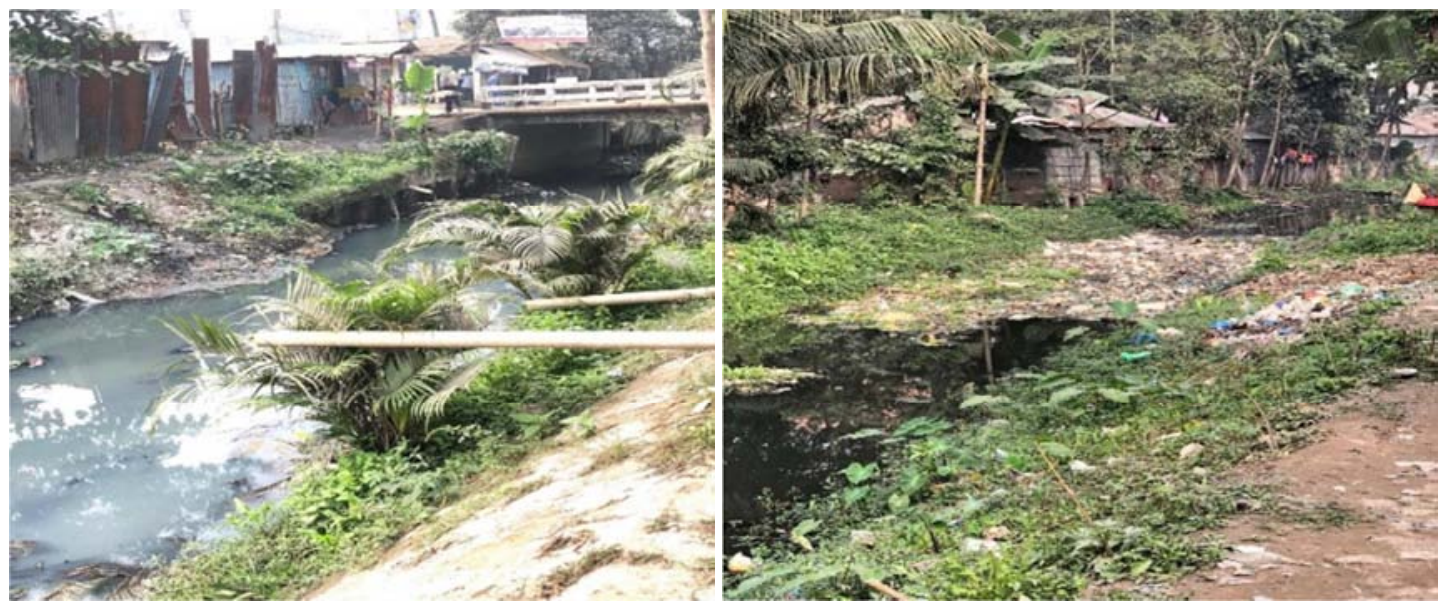

Figure 7. Present condition of ShamaSundori Canal.

\subsubsection{Poor Waste Management System}

The city dwellers produce approximately 10-14 tons of solid waste per day and at least 200 hospitals/clinics add 1.5 tons of medical waste in the city region. [16] But there are only 200 waste collection points to dispose the huge number of wastes which covers only $30 \%$ of the suburban area. From wards (16-30), only 59 out of 85 concrete dustbin and 120 out of 151 ring dustbins are used. The rest wastes are

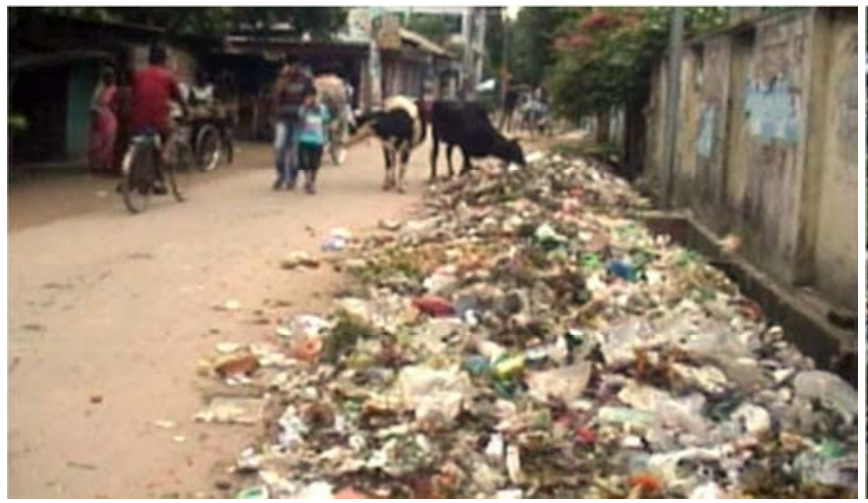

Figure 8. Roadside dustbin and Nachnia beel dumping point

\subsubsection{Lack of Awareness}

Not only the ignorance of authority but also the inhabitants are equally responsible for water logging. Throwing domestic and industrial waste and garbage into drains and canal hinder for passing water. Roadside hotels and stalls throwing their residue such as ash, tea, vegetables and plastic substances etc. frequently dumped into road side areas and open fields, eventually find their way into drains and canal. The only dumping point Nachnia bill is not sufficient enough to carry the city load, also causing environmental pollution. Collection of wastes from the dumping points by RpCC authority are also irregular. Inadequate number of waste collection points, equipment and manpower are the vital causes of poor SWM system.

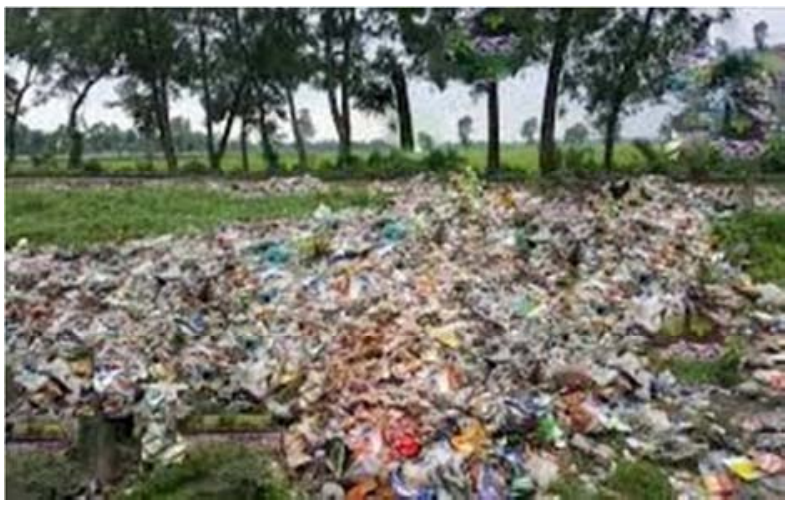

into nearby drains that causes clogging of the drains. Irregular drain cleaning is also responsible for drain blockage.

\subsection{Effects of Water Logging in Urban Life}

The dwellers of Rangpur, previously known as drought prone area, used to desire for rain. Now, rain has become a 
matter of anxiety due to water logging. Waterlogging has crippled the whole of Rangpur city, much to the sufferings of local residents. For example, 50,000 residents of the city corporation were marooned as the poor drainage system was preventing the rainwater from draining away after a torrential rainfall of $433 \mathrm{~mm}$ for only few hours in September, 2020.
The sufferings of people knew no bounds as daily lives were hampered. Lack of drinking water, foods and hygienic environment made city life more miserable. A survey has been conducted through questionnaire in the most waterlogged area (16-30 no. wards) to find out and analyze the effects of water logging in daily urban life.

Table 5. Effects of water logging.

\begin{tabular}{llll}
\hline Categories & Percentage & Categories & Percentage \\
\hline Damage of houses & 62 & Destruction of drains & 65 \\
Damage of properties & 54 & Disturbance in traffic movements & 78 \\
Scarcity of drinking water & 64 & Water and environmental pollution & 57 \\
Unavailability of foods & 47 & Increase of water borne diseases \\
Damage of agriculture & 52 & Sanitation problem & 53 \\
Loss of livestock & 11 & Increase of insects & 67 \\
Disturbance in daily life & 93 & Hamper of livelihood & 38 \\
Damage of roads and bridges & 72 & Availability of reliefs and funds \\
\hline
\end{tabular}

Table 6. Proposed Drainage \& SWM Infrastructures.

\begin{tabular}{|c|c|c|c|c|c|}
\hline Drainage & & & SWM & & \\
\hline Categories & Present (km) & Proposed Quantity (\%) & Categories & Present (Nos) & Proposed Quantity (Nos) \\
\hline Primary Drain & 20 & 93 & Transfer station & 0 & 4 \\
\hline Secondary Drain & 60 & 83 & Dumping Station & 1 & 2 \\
\hline Tertiary Drain & 90 & 5 & Roadside Moveable Dustbins & 156 & 250 \\
\hline Khal/Canal & 60 & 28 & Compost \& Solid Waste Recycle Plants & 0 & 2 \\
\hline
\end{tabular}

\section{Proposed Solution of Water Logging in RpCC}

To solve the water logging problem at first the most risked areas should be identified. The priority should also be given to those areas according to their vulnerability level. Analyzing the field survey and $\mathrm{RpCC}$ data high priorities is proposed to the central area of City Corporation. Priority is considered based on the population projection as these areas holds more than half of the population. These areas are assumed to have the most infrastructure density in upcoming years.

High Priority: (16-28) no wards

Medium Priority: (14-16) \& (31-33) no wards

Low Priority: (1-13) no wards

The drainage and SWM facilities have to be improved and regulated proportional to the increased population and household. The surrounding areas of this main central point can be considered as medium prioritized area and also provide a connected drainage and SWM network. Not only depending on ShamaSundori and KD canals, the Khoksa Ghagot, Burail River and main Ghagot River can be included as outfalls in the drainage network. The proposed drainage and SWM infrastructure are given below.

\section{Conclusion and Recommendation}

The water logging problem is one of the major threats for the Rangpur City in recent future. A proper organized plan should be imposed considering the main causes of water logging such as inactive drainage system, inadequate solid waste management system and unsatisfactory maintenance. These are the criteria that should be fulfilled by an urban city to keep pace with the rapidly growing urbanization. From the analysis of field survey and RpCC data, high emphasis should be given on wards no 16-28 and medium emphasis should be given to $14-16$ and $31-33$ no wards. Additional second level drains should be constructed in the 19-26 no wards and third level drains should be constructed in 17-27 no wards to endure the load. The excess rain water of the middle, southern, western and northern part of the city can be drained out through 4-5 major drains connected respectively to the ShamaSundori canal and KD canal, Khoksha Ghagot, main Ghagot and Burail River. The drainage system will collapse if there is no proper Solid Waste Management System. To run an active SWM system RpCC needs to increase dustbins for each ward with regular maintenance. The different projects and initiatives taken by $\mathrm{RpCC}$ and other responsible authorities need to have coordination for the ultimate betterment of the City.

\section{Acknowledgements}

This study becomes a reality with the kind support and help of many individuals. Cordial gratitude to Md. Mostafizur Rahman Mostofa, Mayor, Rangpur City Corporation for his support. Special thanks to Md. Azmat Ali, Executive Engineer, Rangpur City Corporation for the valuable information. This study got enlighten with the guidance of Tuhin Wadud, Professor, Department of Bangla, Begum Rokeya University and river-activist. We gratefully acknowledge profound regard to RpCC, BWDB, LGED, and BMD Rangpur Division. Last but not the least, we express our heartfelt thanks to the all respondents of the study area 
for their time and valuable opinions.

\section{References}

[1] "March 2014 JAPAN INTERNATIONAL COOPERATION AGENCY PADECO Co., Ltd.," vol. 6, no. March, pp. 14-61, 2014.

[2] R. Management and M. Bhashani, "EFFECT OF WATER LOGGING IN TANGAIL PAURASHAVA," vol. 6, no. December, pp. 11-20, 2016.

[3] L. A. K. \& S. A. M. R. HASAN, M. T. HOSSAIN, "SEASONAL WATER LOGGING PROBLEM IN AN URBAN AREA OF BANGLADESH: A STUDY ON PABNA POURASHAVA," in 1st National Conference on Water Resources Engineering (NCWRE 2018), 2018.

[4] Wadud, T. (2020). "Burdens of Rangpur City", Daily Prothom Alo, Department of Bangla, Begum Rokeya University and river-activist. 28 September, 2020. 16: 04.

[5] L. A. Badal, "Waterlogging cripples Rangpur city after record rainfall," Dhaka Tribune. [Online]. Available: https://www.dhakatribune.com/bangladesh/nation/2020/09/28/ waterlogging-cripples-rangpur-city-after-record-rainfall. [Accessed: 10-Aug-2021].

[6] N. I. Raju, "Rangpur city under water!," TBS News. [Online]. Available: https://www.tbsnews.net/bangladesh/rangpur-cityunder-water-138334.

[7] A. C. Study, O. N. Water, L. Problems, I. N. An, U. Area, and P. A. Solutions, "Id: Sme028 a Case Study on Water Logging Problems in an Urban Area of," vol. 2014, no. September, pp. 26-28, 2014.
[8] W. Islam and S. C. Sarker, "Monitoring the Changing Pattern of Land Use in the Rangpur City Corporation Using Remote Sensing and GIS," J. Geogr. Inf. Syst., vol. 08, no. 04, pp. 537-545, 2016.

[9] M. A. Ashraf and M. S. A. Chowdhury, "Drainage Planning in the Cities of Bangladesh: Case Study of Drainage and Water Logging in Chaktai Commercial area, Chittagong," J. Bangladesh Inst. Planners, vol. 2, no. January 2012, pp. 49-60, 1970.

[10] M. S. H. S. Md. Mijanur Rahman Bappi, Md. Samsuzzaman, Shafayat Shikdar, Md. Sujon Miah, "Water Logging and Drainage System of Rangpur City Corporation (RCC, Ward No. 18 and 20)" 2015.

[11] M. Sarker and M. Rahman, "Assessment of Solid Waste Management Process in Rangpur City Corporation Area," $J$. Geogr. Environ. Earth Sci. Int., vol. 16, no. 3, pp. 1-10, 2018.

[12] K. G. Tawhid, "Causes and Effects of Water Logging in Dhaka City, Bangladesh," TRITA-LWR Master Thesis Dep. L. Water Resour. Eng. R. Inst. Technol., p. 75, 2004.

[13] M. Rahaman, N. Hossain, A. Nurain, P. Sarker, and S. Ichihara, "Investigation on Causes and Effects of Waterlogging in the Southern Part of Bangladesh,” Manag. Sustain. Dev., vol. 12, no. 2, pp. 4-11, 2020.

[14] "Rangpur City Corporation." [Online]. Available: http://www.rpcc.gov.bd. [Accessed: 08-Oct-2021].

[15] “Rangpur Weather Office Annual Report,” 2020.

[16] M. Edrish and M. Ferdous, "Role Of Compact Township And Its Constraints In Achieving Environmental Sustainability In Bangladesh-A Case Study Of Rangpur Union," 3rd Int. Conf. Adv. Civ. Eng., no. December, pp. 611-616, 2013. 